\title{
Comparison of Violet, Red, and Green Light on Early-Stage Common Bean (Phaseolus vulgaris L.) Development
}

\author{
AARON ZIEGLER', Seven Hills High School, Cincinnati, OH, USA.
}

ABSTRACT. The energy efficiency of light-emitting diodes (LEDs) makes them attractive for indoor plant lighting. LEDs, however, do not produce broad-spectrum light efficiently. The effects of LED lighting on common bean (Phaseolus vulgaris L.) growth are not well known. This study sought to find the colors of light that most effectively grow common bean plants under indoor conditions. The hypothesis was that red light would promote early common bean growth better, both qualitatively and quantitatively, than violet or green light. After planting the seeds in soil, 20 common bean plants were each grown under red, or green, or violet LED lights (PHILIPS ${ }^{\circledR}$ ) ( 8 watt), or natural sunlight, for 16 days: a total of 80 plants. Bonferroni adjusted $t$-tests showed that the plants under the violet light grew significantly taller than the plants under red or green light with $p$-values 0.000 respectively; the plants under red or green light had significantly larger leaves than those under the violet light with $p$-values 0.000 . Qualitative observations (based upon visual inspections of leaf health, maturity, and root development) revealed the plants under red light were the healthiest, most mature, and exhibited the most developed roots-followed by those under green light. The findings of this study suggested early common bean growth performed better under red light than under violet or green light.

OHIO J SCI 120(2):49-56

\section{INTRODUCTION}

Light is an important asset in plant development and growth. As human space travel moves further away from Earth, artificial light will be needed to grow food-due to the lack of sunlight in deep space. Light-emitting diodes (LEDs) are one of the most promising technologies for closed-environment plant lighting systems (Massa et al. 2015) and especially for space crop applications (Mitchell 2012; Poulet et al. 2014). An advantage of LEDs over incandescent bulbs is that LEDs give off virtually no heat, allowing plants to be close to the light source and not be damaged, thus saving greenhouse space (Mitchell 2012). Another benefit of LEDs is that they last for up to 60,000 hours, 6 times longer than the closest competing compact fluorescent lamp (CFL) bulbs (Feiadmin 2014). When comparing LEDs and highpressure sodium lamps (HPS), LEDs use less power per unit growing-surface area than HPS: a significant energy savings (Poulet et al. 2014).

Different visible colors of light, determined by wavelength, affect plants in different ways (Britz and Sager 1990; Gómez and Mitchell 2015). Red light promotes leaf expansion and biomass accumulation; additionally, red contributes to a phytochrome photostationary state (PPS) that can

${ }^{1}$ Address correspondence to Aaron Ziegler, 9541 Bluewing Terrace, Cincinnati, OH 45241, USA.

Email: aaronziegler21@gmail.com determine flowering, dormancy, and other important photomorphogenic responses of plants, such as seed germination (Mitchell and Stutte 2015). Blue light affects phototropism, stomatal aperture, chlorophyll content, antioxidant levels, and leaf thickness (Olle and Viršile 2013). Green light was once thought unnecessary for plants, but recent studies have found this wavelength penetrates the canopy and supports the leaf growth on lower levels (Mitchell and Stutte 2015). Studies have also shown that different plant species thrive in different light settings: some species grew well under one light setting, while other species did not (Massa et al. 2015). Therefore, studying the impact of light wavelength on many different plant species is necessary.

The purpose of this study was to identify the color of light (wavelength) that is best for growing common bean plants in settings where natural light is not available. The 3 colors chosen were based on the work of Mitchell and Stutte (2015). Red light was used as the control. Red was chosen because there was much literature on the effect of red light on plants (Folta 2004; Suyanto et al. 2012; Olle and Viršile 2013; Poulet et al. 2014; Massa et al. 2015). This could help ensure results of the current 
research matched the work of others. Violet light was chosen because it was high-energy visible light, and there had been limited research performed on its effect on plants. Green light was chosen because it was previously thought to be insignificant in plant growth and development; however, new research found that it impacted the plant during seedling and leaf growth stages (Folta 2004; Wang and Folta 2013). Finally, natural sunlight was chosen as a reference, as the ultimate goal of growing plants under artificial light is to match development under natural sunlight.

The common bean (Phaseolus vulgaris L.) was chosen for this study for 2 reasons: (1) no previous study was found on the effect of light wavelength on this species and (2) the capability of common beans to be a fast-growing and healthy food source. The findings from this study could be applied to mass production of common beans, and other plants as well.

The objective of the current study was to identify the wavelength of light that best promotes earlystage common bean growth. It was hypothesized that common beans grown under red light would perform better, in the early stage, and on both qualitative and quantitative measures, than those under green or violet light.

\section{METHODS AND MATERIALS Growing Conditions}

Threeequallysized cardboardboxes, $30.5 \times 42 \times 44.5$ $\mathrm{cm}(12.0 \times 16.5 \times 17.5 \mathrm{inch})$, were used to house the plants. The bottom of each box was removed. Three, 8-watt LED lamps (PHILIPS $\left.{ }^{\circledR}\right)-1$ each of red $(650$ to $625 \mathrm{~nm}$ ), green ( 560 to $520 \mathrm{~nm}$ ), and violet ( 450 to $380 \mathrm{~nm}$ ) color-were fit into light-bulb sockets. Each LED was mounted to the center of a piece of plywood, $30.5 \times 42 \mathrm{~cm}(12 \times 16.5 \mathrm{inch})$. Each piece of plywood, with the lamp directed downward, was placed on top of a cardboard box. All seams were sealed with opaque duct tape to block any outside light. The lights were plugged into a power strip which, in turn, was controlled by an outlet timer regulating a 16:8 light-dark cycle.

The wavelength output from the LED lamps was tested using an Adafruit ${ }^{\circledR}$ Metro M0 Express microcontroller (Adafruit Industries LLC, New York, New York) with an ATSAMD21G18 chip (Microchip Technology Inc, Chandler, Arizona) and CircuitPython ${ }^{\circledR}$ _ run with custom-written
CircuitPython computer code-connected by wire to an Adafruit AS7262 6-Channel Visible Light / Color Sensor Breakout (Adafruit).

Common beans were grown from Burpee ${ }^{\circledR}$ seeds (W. Atlee Burpee \& Co, Warminster, Pennsylvania) in $16 \mathrm{~cm}$ diameter plant pots. Each pot was filled with $700 \mathrm{~g}$ indoor potting soil consisting of 60 to $70 \%$ sphagnum peat moss, coir, perlite, "a wetting agent," and fertilizer $(0.135 \%$ ammoniacal nitrogen, $0.135 \%$ nitrate nitrogen, $0.13 \%$ available phosphate, 0.19\% soluble potash) (Burpee). The plants grown using natural light were placed under a skylight, next to windows, and exposed to natural light from sunrise to sunset. All trials in the current study ran during June to August of 2018 and 2019. These natural-light trials were used as a reference group, not a control group; therefore, the conditions such as light-dark cycle, temperature, and humidity were not set to match the LED groups. These aforementioned conditions were, however, kept consistent among the 3 LED groups.

\section{Procedure}

Five trials were conducted, each trial consisting of 4 plants under each of the 4 colors of light: a total of 80 plants. Soil was placed into the pots. Two seeds were placed at least $8 \mathrm{~cm}$ apart in each pot, and covered with soil to a depth of $3 \mathrm{~cm}$. Next, 2 pots were placed under each light in each cardboard box. Each pot was watered with $120 \mathrm{ml}$ of water immediately after sowing the seeds, and 40 to $50 \mathrm{ml}$ of water every day until the end of the trial. Once seeds germinated, plant height and leaf width were measured once daily. Measurements (in millimeters) were taken by hand with a ruler. Plant height was measured by extending the plant to its fullest height (including leaves), and measuring from the base of the plant to the top of the stem. Leaf width was measured by choosing the largest leaf of the plant, then measuring the widest part perpendicular to the midrib of the leaf. The data were recorded in Excel. Qualitative plant conditions, such as leaf color and leaf appearance, were also observed and recorded. On the last day of the trial, the plants were removed from the soil and the root appearance was observed qualitatively.

Based on a preliminary trial, conducted before the formal trials, it was decided the study would include the first 2 weeks of plant life-defined as early-stage common bean growth. In the preliminary 
trial, plant height had plateaued around 10 to 11 days after sowing; additionally, although leaf width continued to increase, growth rate began to slow. Finally, flower buds began to emerge on plants under red light, signaling a new stage of development. Data collection, therefore, ended on the 16th day after planting the seed. The data collected on the last day of each trial was used for analysis.

\section{Variables}

Two sets of dependent variables were collected and observed: quantitative dependent variables (plant height, leaf width) and qualitative dependent variables (leaf appearance, maturity-development stage, root appearance). The independent variable was the color of light (red, green, or violet). Throughout the experiments, the following were set as constants for the artificial-light treatment groups: energy output (8 watts), type of light (light from LEDs), length of time the plant was exposed to light every day (16 hours), type of soil (indoor potting soil), amount of soil per pot (700 g), temperature (20 to $\left.24^{\circ} \mathrm{C}\right)$, amount of water per day per pot (40 to $50 \mathrm{ml}$ ), type of plant (common bean (Phaseolus vulgaris)), type of pot (plastic), and size of pot (18 $\mathrm{cm}$ diameter $\times 20 \mathrm{~cm}$ tall $)$.

\section{Data Analysis}

For the 2 quantitative measures, plant height and leaf width, an ANOVA was performed on each measure to test any differences on the measures among the 4 groups (red, green, violet, and natural light). When the ANOVA showed a statistically significant difference among the 4 groups, Bonferroni adjusted $t$-tests were performed to identify statistically significant differences between any 2 groups. All data analysis was performed in Excel.

\section{RESULTS}

\section{Quantitative Data}

The plants grown under violet or natural light averaged 45 to $50 \mathrm{~mm}$ greater in height than those under green or red light. However, the plants grown under red or green light had much wider leaves than those under violet or natural light; those under the red light had the largest average leaf width of $80 \mathrm{~mm}$, and those under the natural light had the smallest average leaf width of $36 \mathrm{~mm}$ (Table 1, Figs. 1 and 2).

Tables 2, 3, and 4 show a statistical analysis of the data. For plant height, ANOVA analysis showed statistically significant differences between the heights among the 4 groups with a $p$-value $=0.000$. $t$-tests with Bonferroni adjustment (adjusted alpha $=$ $0.05 / 6=0.008$ ) found that 4 pairwise comparisons were significant: the average plant height under green light vs. those under violet light $(p$-value $=$ $0.000)$, the average plant height under green light vs. those under natural light $(p$-value $=0.000)$, the average plant height under red light vs. those under violet light $(p$-value $=0.000)$, and the average plant height under red light vs. those under natural light $(p$-value $=0.000)$. The other 2 comparisons were non-significant, with $p$-values of 0.534 and 0.690 for comparisons between plants under violet or natural light, and between plants under red or green light, respectively.

Similar statistical analyses were performed for leaf width. ANOVA showed statistically significant differences in the leaf width among the 4 groups with $p$-value $=0.000$. $t$-tests with Bonferroni adjustment (adjusted alpha $=0.05 / 6=0.008$ ) found that 4 pairwise comparisons were significant with $p$-values $=0.000$ : the average leaf width under green light vs. those under violet light, those under green light vs. those under natural light, those under red

Table 1

Average plant height and leaf width under each light at the end of trials

\begin{tabular}{lrrrc}
\hline \hline & \multicolumn{4}{c}{ Color of light } \\
\cline { 2 - 5 } Growth parameter & \multicolumn{1}{c}{ Violet } & \multicolumn{1}{c}{ Red } & \multicolumn{1}{c}{ Green } & Natural \\
\hline Plant height $(\mathrm{mm})(\mathrm{n}=80)$ & $332 \pm 23.2^{\mathrm{a}}$ & $285 \pm 30.7^{\mathrm{b}}$ & $280 \pm 47.7^{\mathrm{b}}$ & $326 \pm 39.8^{\mathrm{a}}$ \\
Leaf width $(\mathrm{mm})(\mathrm{n}=80)$ & $43 \pm 10.3^{\mathrm{c}}$ & $80 \pm 22.1^{\mathrm{d}}$ & $76 \pm 17.9^{\mathrm{d}}$ & $36 \pm 7.1^{\mathrm{c}}$ \\
\hline
\end{tabular}

a, b, c, d Values for a given parameter sharing the same letter are not statistically different by

Bonferroni adjusted $t$-tests (Table 4). 


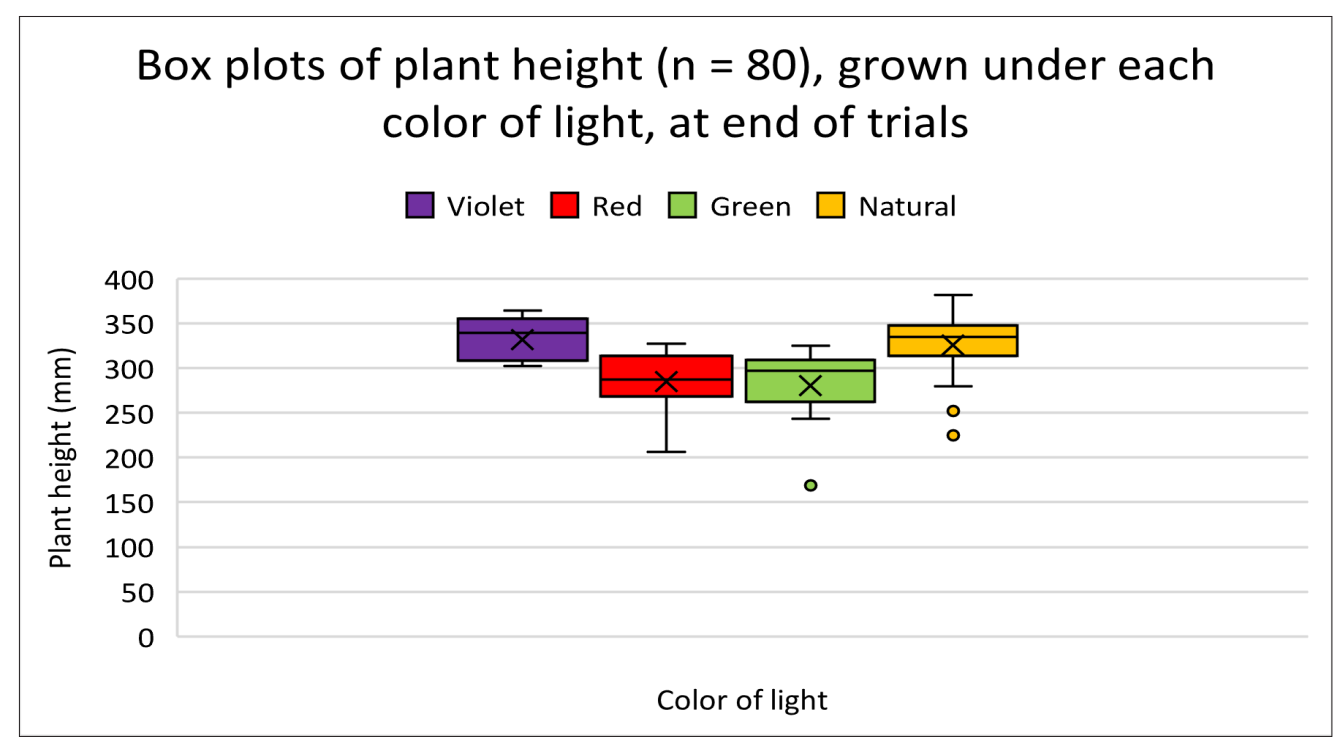

FIGURE 1. Box plots of plant height $(\mathrm{mm})$ of each group of 20 plants at the end of trials, 16 days after seeds were sown. Groups were violet light, 450 to $380 \mathrm{~nm}$ (purple box); red light, 650 to $625 \mathrm{~nm}$ (red box); green light, $560 \mathrm{to} 520 \mathrm{~nm}$ (green box); and natural light (yellow box). The " $x$ " denotes the mean, the line within the box denotes median, the colored box denotes 2 nd and 3rd quartile of the data, the whiskers denote 1 st and 4th quartiles of the data, and the dots denote extraneous values.

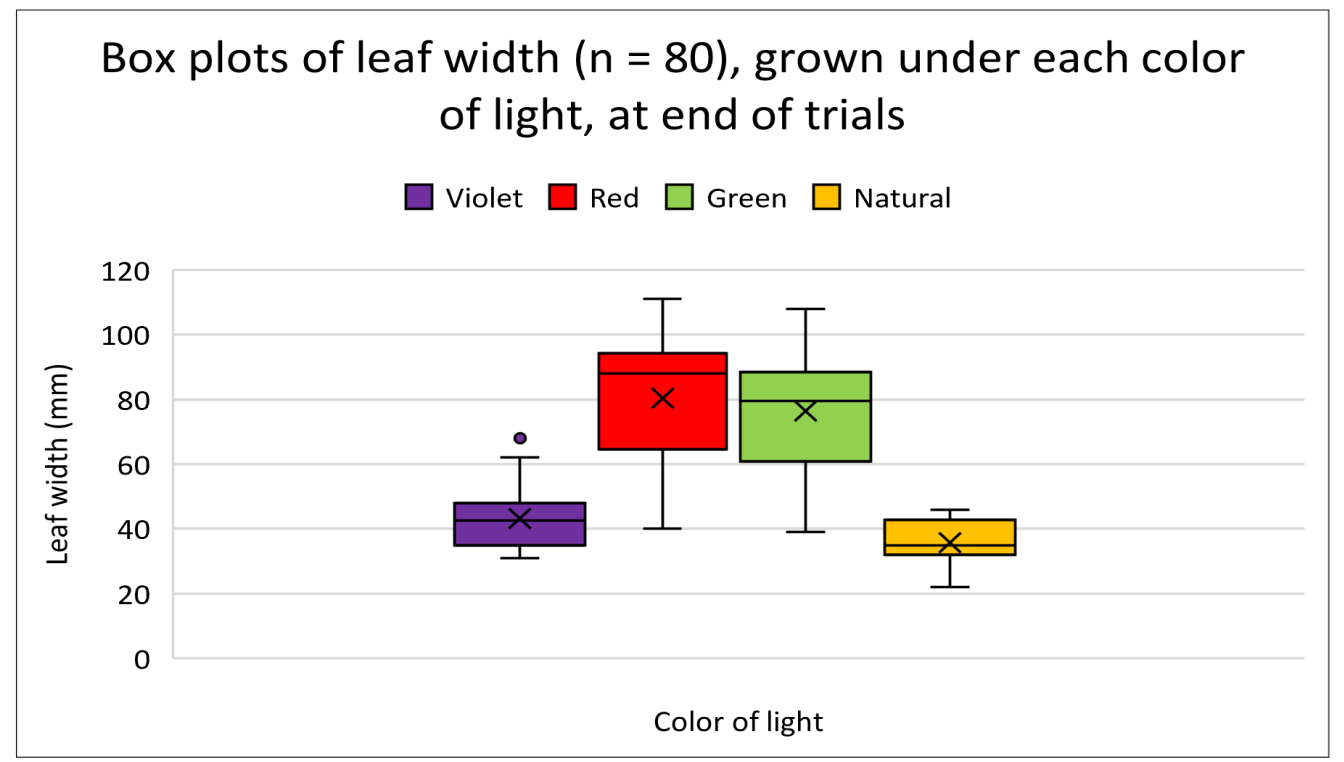

FIGURE 2. Box plots of leaf width $(\mathrm{mm})$ of each group of 20 plants at the end of trials, 16 days after seeds were sown. Groups were violet light, 450 to $380 \mathrm{~nm}$ (purple box); red light, 650 to $625 \mathrm{~nm}$ (red box); green light, 560 to $520 \mathrm{~nm}$ (green box); and natural light (yellow box). The " $x$ " denotes the mean, the line within the box denotes median, the colored box denotes 2 nd and 3rd quartile of the data, the whiskers denote 1 st and 4 th quartiles of the data, and the dots denote extraneous values.

Table 2

ANOVA analysis on plant height

\begin{tabular}{lrrrlll}
\hline \hline Source of variation & \multicolumn{1}{c}{ SS } & $\boldsymbol{d f}$ & $\boldsymbol{M S}$ & $\boldsymbol{F}$ & $\boldsymbol{p}$-value & $\boldsymbol{F}$ crit \\
\hline Between groups & 42738.7 & 3 & 14246.23 & 12.009 & 0.000 & 2.725 \\
Within groups & 90155.5 & 76 & 1186.26 & & & \\
Total & 132894.2 & 79 & & & & \\
\hline
\end{tabular}


light vs. those under violet light, and those under red light vs. those under natural light. The other 2 comparisons were not significant, with $p$-values of 0.009 and 0.538 for comparisons between plants under violet or natural light, and under red or green light, respectively.

\section{Qualitative Data}

Leaf color. The plants under the violet light had either completely yellow or slightly yellow leaves. The plants under the red light generally had green leaves, except 5 plants which had slightly yellow leaves (but less yellow than any of the plants under the violet light). The plants under the green light had slightly yellow leaves, and some of the leaves were translucent. The plants under the natural light were mostly green, with slightly yellow edges on 2 leaves among all leaves.

Leaf visual appearance. The plant leaves under the violet light were shriveled and dry around the edges, and most had tears. The plant leaves under the red light were not shriveled or dry, had no tears on the leaves, and seemed to be the healthiest of all the plants observed. The plant leaves under the green light were shriveled around the edges and slightly dry, had many tears on the leaves, and some had holes. Some leaves had turned slightly translucent and lost all pigmentation in parts of the leaves. The plant leaves under the natural light were slightly shriveled, and just 2 to 3 leaves total had tears.
Plant maturity. This was defined by the specific stage of development: first-stage leaf growth (2 leaves), second-stage leaf growth (3 additional leaves), and third-stage leaf growth (another 3 additional leaves). At the end of the trials, 12 of the 20 plants under the red light were in stage 2 or 3 - and 2 plants had flower buds (Table 5). Half of the plants under the green light were in stage 2 or 3. Half the plants under the violet light were in stage 2; however, most of them were in early stage 2 , and none had entered stage 3 . All leaves on plants under the violet light were smaller than those under the red or green light. Plants under the natural light were the least developed, with only 4 of the 20 progressing beyond stage 1 , but their leaves were bigger and greener than those under violet light.

Root visual appearance. Roots were observed at the end of the trials by gently removing the plants and soil from the pots, then rinsing the soil off the roots with water. The plants under the violet light had long, thick, primary roots—but few secondary roots. The plants under the red light had a long, thick, primary root-with many equally long secondary roots. The plants under the green light had no clear primary root. These roots were thin and the shortest among the plants observed. The plants under the natural light had a long primary root with about 6 to 8 secondary roots of the same length, but thinner (Table 6).

Table 3

ANOVA analysis on leaf width

\begin{tabular}{llrrrrl}
\hline \hline Source of variation & \multicolumn{1}{l}{ SS } & \multicolumn{1}{c}{$\boldsymbol{d f}$} & \multicolumn{1}{l}{ MS } & $\boldsymbol{F}$ & $\boldsymbol{p}$-value & $\boldsymbol{F}$ crit \\
\hline Between groups & 31005.45 & 3 & 10335.15 & 42.744 & 0.000 & 2.725 \\
Within groups & 18376.10 & 76 & 241.79 & & & \\
Total & 49381.55 & 79 & & & & \\
\hline
\end{tabular}

Table 4

Bonferroni adjusted $t$-test $p$-values for pairwise plant height and leaf width comparison ${ }^{* *}$

\begin{tabular}{llllllll}
\hline \hline & \multicolumn{3}{c}{ Plant height } & & \multicolumn{3}{c}{ Leaf width } \\
\cline { 2 - 4 } \cline { 6 - 8 } Color of light & Red & Green & Natural & & Red & Green & Natural \\
\hline Violet & $0.000^{*}$ & $0.000^{*}$ & 0.534 & & $0.000^{*}$ & $0.000^{*}$ & 0.009 \\
Red & & 0.690 & $0.000^{*}$ & & 0.538 & $0.000^{*}$ \\
Green & & & $0.000^{*}$ & & & & $0.000^{*}$ \\
\hline
\end{tabular}

* Statistically significant after Bonferroni adjustment.

** The Bonferroni adjusted significant alpha level $=0.05 / 6=0.008$. 
Table 5

Number of plants that reached each maturity level under each light

\begin{tabular}{lllll}
\hline \hline & \multicolumn{3}{c}{ Color of light } \\
\cline { 2 - 5 } Plant maturity & Violet & Red & Green & Natural \\
\hline Leaf stage 1 & 10 & 8 & 10 & 16 \\
Leaf stage 2 & $10^{*}$ & $9^{*}$ & $7^{*}$ & $4^{*}$ \\
Leaf stage 3 & 0 & $3^{*}$ & $3^{*}$ & 0 \\
\hline
\end{tabular}

* One or more plants were not fully developed for that stage.

Table 6

Ranking of root data observed by visual inspection

\begin{tabular}{ll}
\hline \hline Root parameter & Order by color of light from largest to smallest \\
\hline Primary root length & Violet $>$ natural $>$ red $>$ green \\
Root thickness & Red $>$ violet $>$ natural $>$ green \\
Number of branches & Red $>$ green $>$ natural $>$ violet \\
\hline
\end{tabular}

\section{DISCUSSION}

There were clear differences, both quantitatively and qualitatively, among plants grown under the separate colors of light. These differences include plant height, leaf width, root structure, plant maturity, and plant health. Because all LEDs used in this experiment had the same wattage and were from the same manufacturer, it is likely the photosynthetic photon flux output from all 3 LEDs was approximately equal. One factor that could have contributed to the observed plant development differences was the relative photosynthetic efficiency (RPE) of each light wavelength (Fig. 3). The red light has the highest RPE, about $90 \%$, meaning the plants under red light gained more energy than the others.

Additionally, phytochromes likely contributed to the growth differences among the plants under different lights. A phytochrome detects if the plant is being exposed to red (635 to $700 \mathrm{~nm}$ ) or far-red (700 to $800 \mathrm{~nm}$ ) light. The exclusive red-light exposure likely increased $\mathrm{P}_{\mathrm{fr}}$ (the form of phytochrome activated by red light) and triggered more leaf growth for plants under red light. Red light is also known to inhibit internode elongation (Taiz et al. 2014, p. 377), which may explain the shorter plant height under red light. Wang and Folta (2013) also noted green light could influence phytochrome equilibrium favoring $P_{\mathrm{fr}}$ and activating seed germination, which can explain early growth of the plants under green light.
Plants grown under each of the LED lamp colors were compared to those grown under natural light. In this comparison it was found that those under violet light performed worse in leaf health (although the leaves were larger on average) — while those under red light performed better in all leaf aspects - than plants under natural light. Red light provides not only the highest energy efficiency in driving photosynthesis, but also other effects such as phytochrome (Mitchell and Stutte 2015).

The performance of the plants under the green light was better than expected. In addition to RPE and phytochrome, other factors may have influenced the results on plants under green light. Studies have shown that the effects of green light were most evident when overall lighting was low (Wang and Folta 2013). Mitchell and Stutte (2015) reported that intact leaves of lettuce did absorb considerable green light, and certain green wavelengths were even more efficient than those in the blue band. They also reported that green light penetrated the canopy better than red and blue light, thus reaching interior leaf layers where the green light could be absorbed and drive photosynthesis. Wang and Folta (2013) also hypothesized that there were green-light specific sensors to be discovered. The current study showed that when green light was the sole light source, common bean stems and leaves developed reasonably well at the earliest stage of the life cycle. Near the end of the trials, however, some of the plants 


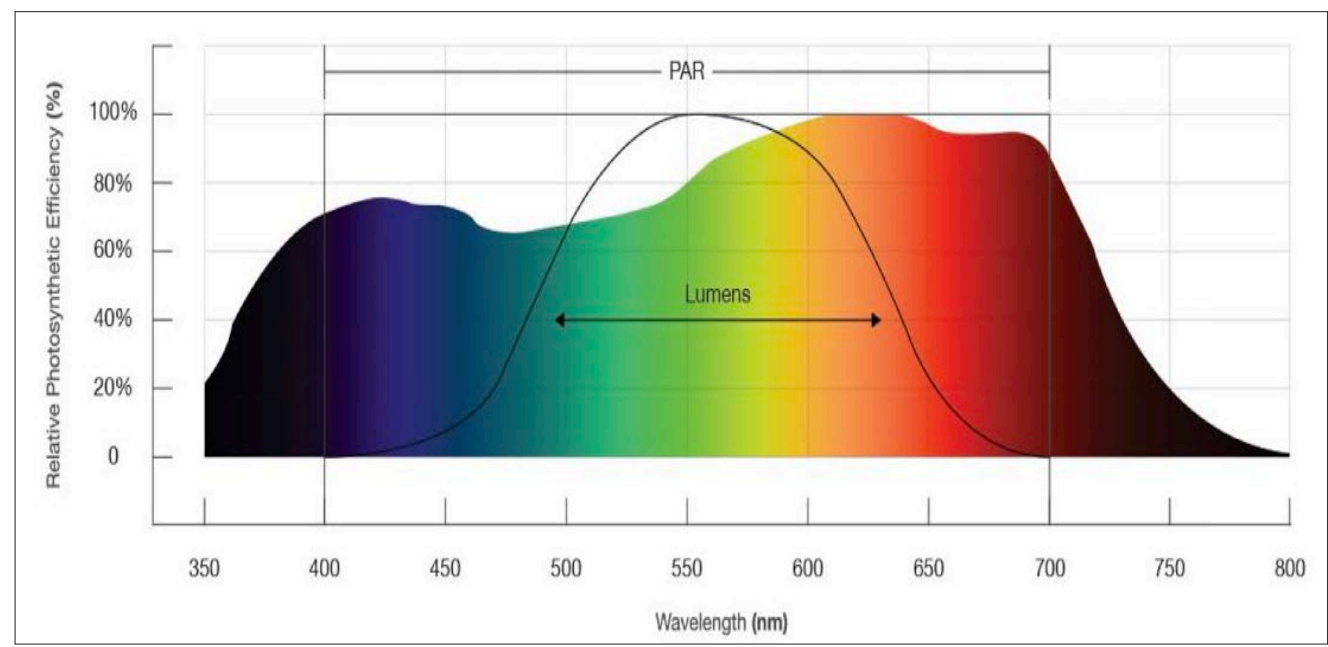

FIGURE 3. Relative photosynthetic efficiency (RPE) curves corresponding to light wavelength (Fluence [accessed 2018])

under the green light developed translucent leaves, indicating pigmentation loss or cell necrosis. Finally, the smaller root structure (compared to plants under the red light) suggested the plants under green light would have difficulties maturing further.

When choosing light for early-stage common bean growth for deep-space travel, and if only 1 wavelength must be chosen, red light should be the first choice-resulting in better plant development and potentially more compact plant size.

\section{Conclusion}

Among all the plant trials, those grown under the red light were most developed at the end of the experiment. This conclusion was supported by the quantitative data of the leaf width of the plants under the red light, but more importantly by the maturity and root observations. Qualitative observation showed plants under the red light developed furthest along the life cycle, with the healthiest leaves and the best root development.

Plants under green light performed better than those under natural light in terms of both leaf width and maturity. However, leaf color and root strength were less than the plants grown under the red light. This presented the question if the plants under the green light would sustain further growth if they continued to mature.
The plants under violet light (despite having taller plant height) developed smaller, less healthy, leaves than those under the red, green, or natural light.

In conclusion, among the 3 tested LED wavelength ranges, red light was the most promising choice for early-stage common bean growth. This result was consistent with previous studies (Olle and Viršile 2013; Massa et al. 2015; Mitchell and Stutte 2015).

Future work could involve increasing the number of plants under each light. Further, a light source that changed intensity during the day could be added, more closely simulating natural light and allowing better comparison between experimental light and natural light.

Ultimately, it is necessary to test the impact of the color of light on the full life cycle of common beans. Given current technology, it is possible to adjust the color of light based on plant life stage. For example, red light for the seedling stage and then a different color for the flowering stage. It would also be informative to test combinations of color effectssuch as a blend of red and green light for early stage, and red and blue light for late stage growth — because there has been no definite conclusion on the impact of blue light on plant growth (Poulet et al. 2014; Mitchell and Stutte 2015). 


\section{LITERATURE CITED}

Britz SJ, Sager JC. 1990. Photomorphognensis and photoassimilation in soybean and sorghum grown under broad spectrum or blue-deficient light sources. Plant Physiol. 94(2):448-454.

https://doi.org/10.1104/pp.94.2.448

Feiadmin A. 2014. What's the difference between a fluorescent light and an LED? [blog]. Frye Electric Inc.: ask the experts blog. [accessed 2018 Nov 29].

http://www.fryeelectricinc.com/2014/04/fluorescent-light-and-an-led/

[Fluence] Fluence by OSRAM. [date unknown]. About PAR, PPF, and PPFD [corporate website, online article]. [accessed 2018 Nov 17].

https://fluence.science/science-articles/horticulture-lighting-metrics/

Folta KM. 2004. Green light stimulates early stem elongation, antagonizing light-mediated growth inhibition. Plant Physiol. 135(3):1407-1416.

https://doi.org/10.1104/pp.104.038893

Gómez C, Mitchell CA. 2015. Growth responses of tomato seedlings to different spectra of supplemental lighting. Hortscience. 50(1):112-118.

https://doi.org/10.21273/HORTSCI.50.1.112

Massa G, Graham T, Haire T, Flemming C 2nd, Newsham G, Wheeler R. 2015. Light-emitting diode light transmission through leaf tissue of seven different crops. Hortscience. 50(3):501-506.

https://doi.org/10.21273/HORTSCI.50.3.501

Mitchell CA. 2012. Plant lighting in controlled environments for space and earth applications. Acta Hortic. 956:23-36. https://doi.org/10.17660/ActaHortic.2012.956.1
Mitchell C, Stutte G. 2015. Sole-source lighting for controlledenvironment agriculture. Washington (DC): NASA. 10 p. Report No.: KSC-E-DAA-TN23510. Contract_grant No.: NNK11EA08C. Available from: NASA Technical Reports Server, document ID 20150009399. https://ntrs.nasa.gov/citations/20150009399

Olle M, Viršile A. 2013. The effects of light-emitting diode lighting on greenhouse plant growth and quality. Agr Food Sci. 22(2):223-234. https://doi.org/10.23986/afsci.7897

Poulet L, Massa GD, Morrow RC, Bourget CM, Wheeler RM, Mitchell CA. 2014. Significant reduction in energy for plant-growth lighting in space using targeted LED lighting and spectral manipulation. Life Sci in Space Res. 2:43-53. https://doi.org/10.1016/j.lssr.2014.06.002

Suyanto H, Rupiasih NN, Handayani D. 2012. Influence of light wavelengths on growth of tomato. Jurnal Bumi Lestari (Journal of Environment). 12(2):338-344.

Taiz L, Zeiger E, Moller IM, Murphy A. 2014. Plant physiology and development. 6th ed. Sunderland (MA): Sinauer Associates. 623 p. ISBN-13: 978-1605352558. Sinauer Associates is now an imprint of Oxford University Press.

Wang Y, Folta KM. 2013. Contributions of green light to plant growth and development. Am J Bot. 100(1):70-78. https://doi.org/10.3732/ajb.1200354 